\title{
Effects of platelet rich plasma on fascial healing in rats with fecal peritonitis ${ }^{1}$
}

\author{
Mustafa Girgin', Kenan Binnetoglu', Kazim Duman'II, Burhan Hakan Kanat ${ }^{\mathrm{IV}}$, Ziya Cetinkaya ${ }^{\mathrm{V}}$, Refik Ayten"v, Yavuz Selim \\ Ilhanv, Necip Ilhan ${ }^{\text {VI, Ibrahim Seker }}{ }^{\text {VII }}$, Necati Timurkaan ${ }^{\text {VIII }}$
}

DOI: http://dx.doi.org/10.1590/S0102-865020160050000004

\begin{abstract}
IAssociate Professor, Department of General Surgery, Faculty of Medicine, Firat University, Elazig, Turkey. Design of the study, surgical procedures, statistical analysis.

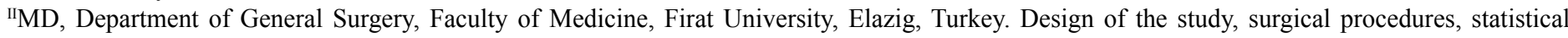
analysis.

IIIMD, Department of General Surgery, Elazig Military Hospital, Elazig, Turkey. Interpretation of data, manuscript preparation and writing.,

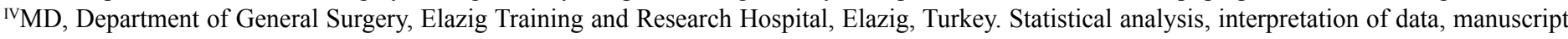
preparation.

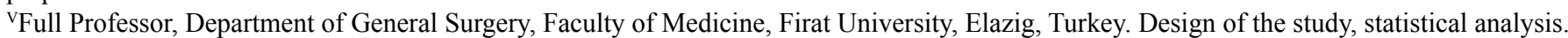

${ }^{\mathrm{V}}$ Full Professor, Department of Biochemistry, Faculty of Medicine, Firat University, Elazig, Turkey. Manuscript preparation, critical revision.

${ }^{V I I}$ Full Professor, Department of Zootechnics, Faculty of Veterinary, Firat University, Elazig, Turkey. Critical revision, final approval.

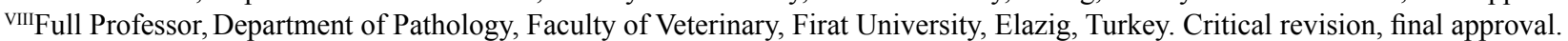

\section{ABSTRACT}

PURPOSE: To evaluate the effects of platelet rich plasma (PRP) on the healing of fascia wherein peritonitis has been created.

METHODS: Twenty eight Wistar Albino rats were divided into four groups. Only a primary fascial repair following laparotomy was performed on Group 1, a primary fascial repair performed and PRP treatment applied following laparotomy on Group 2, and a fecal peritonitis created following laparotomy and a primary fascial repair carried out on Group 3. A fecal peritonitis was created following laparotomy and primary fascial repair and PRP treatment on the fascia was carried out on Group 4.

RESULTS: TNF- $\alpha$ was found to be significantly lower in the control group (Group 1). It was detected at the highest level in the group in which fecal peritonitis was created and PRP applied (Group 4). TGF- $\beta$ was determined as being significantly higher only in Group 4. Histopathologically, the differences between the groups in terms of cell infiltration and collagen deposition were not found to be significant.

CONCLUSION: When platelet rich plasma was given histologically and biochemicaly as wound healing parameters cellular infiltration, collagen accumulation, and tissue hydroxyiproline levels were not increased but neovascularization, fibroblast activation and TNF Alfa levels were increased and PRP accelerated wound healing.

Key words: Platelet-Rich Plasma. Peritonitis. Wound Healing. Rats. 


\section{Introduction}

Wound healing is one of the oldest issues in the literature. Ventral hernia remains one of the most common surgical problems in the USA today, approximately 350,000 cases $^{1}$. Greater problem is the $30-60 \%$ recurrence rate after hernia repair $^{2}$. Despite advance research and prosthesis materials in repair strategies, techniques, and technologies, recurrent herniation continues to be a major issue on patients and the healthcare system ${ }^{3}$.The biggest reason is that they have complications and are the disadvantages of this prosthesis material ${ }^{4}$. Some of these are mesh infection, contraction, erosion, extrusion, and fistula formation. Therefore the rate of hernia formation after laparotomy remains high ${ }^{5}$. Biologic prostheses such as porcine or human acellular dermal matrices are reviled for their high mesh failure rates due to unsuccessful tissue incorporation or enzymatic- immunologic reaction ${ }^{6}$.

Autologous Platelet-rich plasma (PRP), recently, has become popular as a treatment modality in the areas of orthopedic and trauma surgery, spinal surgery, plastic-reconstructive surgery, oral and maxillofacial- dental surgery, ophthalmological surgery, heart by-pass surgery and burns ${ }^{7-9}$. It contains the growth factors; platelet-derived growth factor (PDGF), epidermal growth factor,fibroblast growth factor(FGF), transforming growth factor$\beta$ (TGF- $\beta$ ), insulin-like growth factor (IGF-I, IGF-II), endothelial cell growth factor and vascular endothelial growth factor (VEGF). Besides, it includes bioactivefactors or non-growth factors which normal wound healingagents; serotonin, histamine, dopamine, calcium, adenosine, fibronectin, fibrin, and vitronectin ${ }^{7}$. They have been found to expedite epidermal, epithelial, and endothelialregeneration, aggravating angiogenesis, stimulate soft tissue healing, enhance the hemostatic response, decrease dermal scarring, increase collagen synthesis and assist cell migration ${ }^{10}$.

In this study, we aimed a unique experimental technique on rats. After performing fecal peritonitis, PRP was applied locally to see effects on fascia healing with the consideration of positive effect on wound healing.

\section{Methods}

Our study was conducted at Firat University, Faculty of Medicine, Laboratory Animal Breeding and Experimental Research Center with permission No. 09 dated 01.10.2012 from the Firat University Rectorate, Laboratory Animals Ethics Board Chair.

In order to reduce genetic differences, twenty eight 5 months-old Wistar Albino rats, ranged 223-264g in weight were obtained from the same animal laboratory to be used in the experiments. The animals were fed with standard laboratory feed and tap water and kept in appropriate cages at $22 \pm 2^{\circ} \mathrm{C}$ temperature where a 12 hour light/12 hour dark environment was provided.

The rats were divided randomly into four groups $(n=7$ in each group). Only a primary fascial repair following laparotomy was performed on Group 1 (Control Group), a primary fascial repair following laparotomy and PRP treatment on the fascia was carried out in Group 2 (PRP group), and a fecal peritonitis was created following laparotomy and primary fascial repair was implemented in Group 3 (Fecal peritonitis group). A fecal peritonitis was created following laparotomy and primary fascial repair implementation and PRP applied on the fascia in Group 4 (Fecal peritonitis + PRP group). All groups were taken to a room allocated to them, placed into cages and monitored under expert veterinary supervision.

\section{Preparation of platelet rich plasma}

$1.5 \mathrm{ml}$ of blood drawn from the renal level of the inferior vena cava was taken from each rat for use in themselves, put into EDTA containing tubes and subjected to centrifugation at 5600 rpm (Figure 1).At the end of the process, the blood was divided into three layers, namely a platelet poor plasma, erythrocytes and a yellowish portion containing platelets. The platelet poor plasma part was discarded and the remaining part was centrifuged again at $2400 \mathrm{rpm}$. At the end of this process, the erythrocytes was separated, yielding PRP.
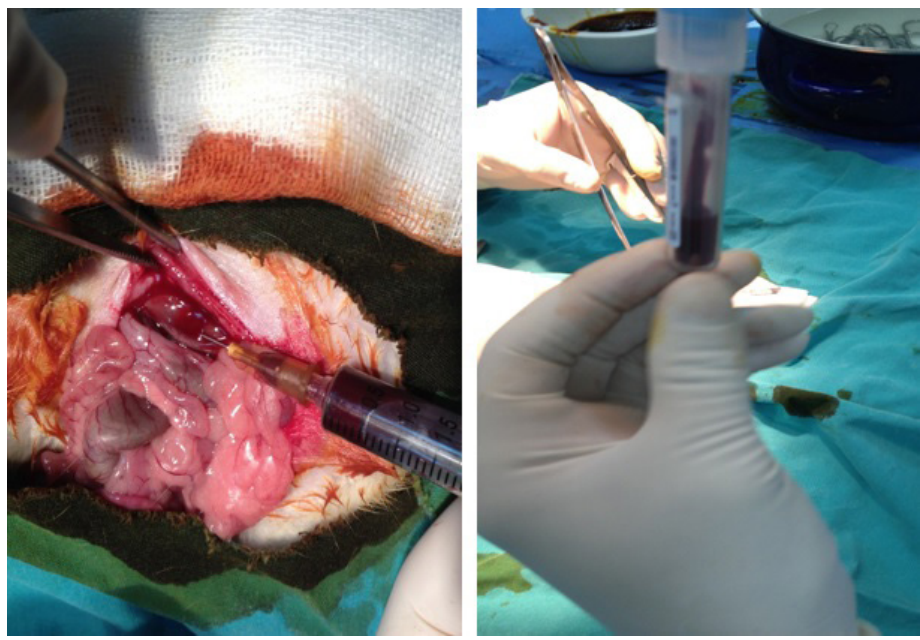

FIGURE 1 - Blood drawn from the renal level of the inferior vena kava was taken, put into EDTA containing tubes. 


\section{Surgical procedure}

Ketamine hydrochloride $50 \mathrm{mg} / \mathrm{kg}$, Xylazine hydrochloride $5 \mathrm{mg} / \mathrm{kg}$ was delivered intramuscularly, achieving appropriate depth of anesthesia and the abdominal wall was shaved, cleansing it with $10 \%$ Iodine povidone solution and covered with a sterile drape. With a $4 \mathrm{~cm}$ abdominal midline incision on the skin, subcutaneous tissues and the fascia was incised, opening the abdomen. After drawing blood for the PRP, the fascia was closed with a 3-0 polyglactin suture and the skin with a 3-0 silk suture in continuation (Figure 2). After 1 week, a total of $5 \mathrm{ml}$ blood was drawn from each of the rats who were decapitated under anesthesia in order to study the biochemical parameters. The skin incision was opened and the fascia incision line excised, including $2 \mathrm{~cm}$ of healthy tissue, with the purpose of histopathological examination and investigation of the tissue hydroxyproline level.
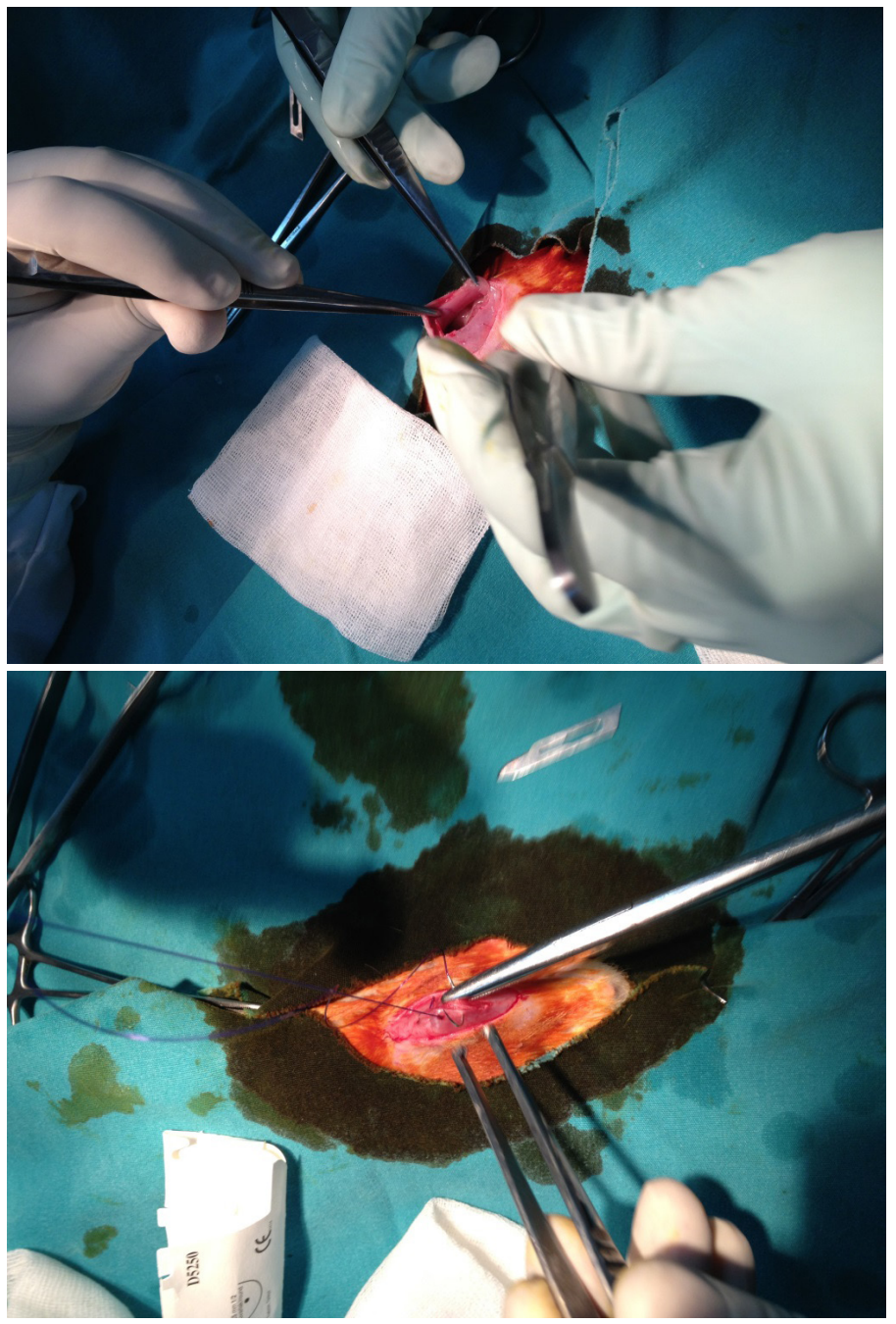

FIGURE 2 - The fascia was closed with a polyglactin suture.

\section{Biochemical examination}

TNF- $\alpha$ (Cat No: CK-E30635) and TGF- $\beta$ levels (Catalogue No: CK-E30636) were measured by the using EastBioPharm(China) ELISA kits. (Cat No: CK-E30191) was used for tissue hydroxyproline levels (Figure 3).
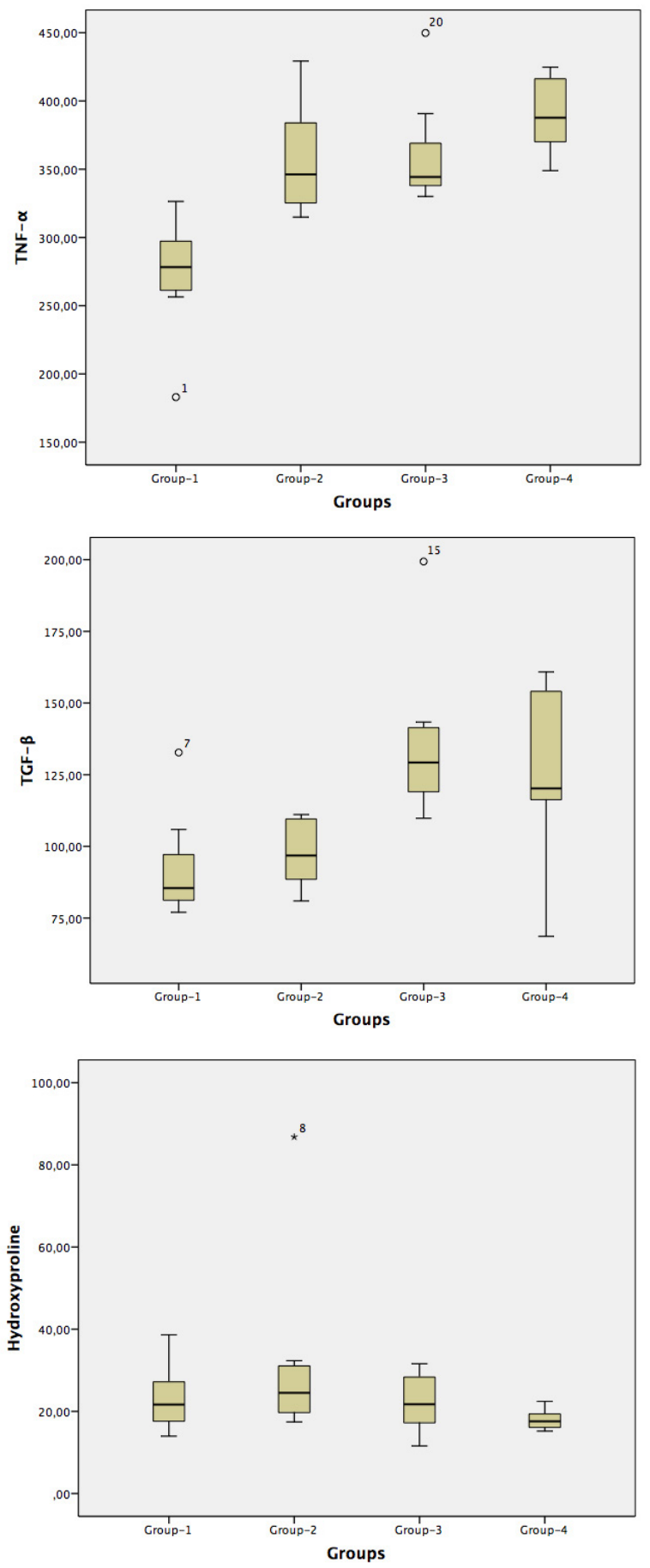

FÍGURE 3 - Comparison of TNF- $\alpha$, TGF- $\beta$ and Hydroxyproline levels between groups.

TNF- $\alpha(\mathrm{pg} / \mathrm{mL})$, tumor necrosis factor alpha; TGF- $\beta$ ( $\mathrm{ng} / \mathrm{mL})$, transforming growth factor beta; Hydroxyproline $(\mu \mathrm{g} / \mathrm{g})$. 


\section{Histopathological examination}

At the end of the study, tissue samples covering the central area and wound edges of rats were obtained, and fixed in $10 \%$ neutral buffered formalin solution. The samples were routinely processed, cut about $5 \mu \mathrm{m}$ thick, and stained with hematoxylinEosin (H-E) and Crossman's trichrome staining methods. Histological changes in the wound areas such as inflammatory cell infiltration, neovascularization, fibroblast activation were scored as follows: 1-no change, 2-mild, 3- moderate, 4- severe. Collagen deposition was classified as: 1- no evidence, 2- light scattering, 3 -abundant fibres, 4 - confluent fibres. The rate of the healing process was determined statistically by considering the scores of the inflammatory cell infiltration as negative value, and the scores of neovascularization, fibroblast activation and collagen deposition as positive values.

Statistical analysis was conducted using the SPSS (v.16) software. The Kruskal-Wallis Variance analysis was used in comparing the groups, while the Mann Whitney U test was used in the paired comparison of the data for which the difference was significant according to this test $(\mathrm{p}<0.05$ was considered statistically significant).

\section{Results}

One rat in the Group 4 was excluded from the study because it died. TNF- $\alpha$ and TGF- $\beta$ levels were measured from the blood drawn on the 7th day of the study. Biopsy specimens taken from the incision wounds were subjected to biochemical examination and their hydroxyproline amounts determined. The resulting data are shown in the table (Table 1). TNF- $\alpha$ levels turned out to be significantly lower in the control group (Group 1) than the other groups $(\mathrm{p}<0.001)$. The highest levels were detected in the group which fecal peritonitis was created and PRP applied (Group 4). TGF- $\beta$ levels were detected significantly higher only in Group $4(\mathrm{p}<0.001)$. Although hydroxyproline levels were numerically the highest in Group 2, the differences between them were not observed to be significant $(\mathrm{p}<0.05)$.

TABLE 1 - Comparison of biochemical and histochemical parameters between groups.

\begin{tabular}{cccccc}
\hline Parameters/Groups & Group-1 & Group-2 & Group-3 & Group-4 & p \\
\hline TNF- $\alpha$ & $272.10 \pm 45.77$ & $358.41 \pm 42.03$ & $362.60 \pm 43.36$ & $389.23 \pm 28.70$ & $<0.001$ \\
TGF- $\beta$ & $93.13 \pm 19.86$ & $97.85 \pm 12.65$ & $123.37 \pm 32.92$ & $137.04 \pm 30.17$ & $<0.001$ \\
Hydroxyproline & $23.41 \pm 8.59$ & $32.90 \pm 24.41$ & $22.29 \pm 7.49$ & $18.04 \pm 2.61$ & 0.186 \\
Inflammatory cell infiltration & $2.29 \pm 1.254$ & $2.00 \pm 1.00$ & $3.29 \pm 0.488$ & $2.86 \pm 0.900$ & 0.427 \\
Neovascularization & $2.57 \pm 0.535$ & $2.71 \pm 0.488$ & $1.86 \pm 0.378$ & $2.57 \pm 0.535$ & $<0.05$ \\
Fibroblast activation & $2.71 \pm 0.488$ & $3.29 \pm 0.488$ & $2.29 \pm 0.488$ & $2.71 \pm 0.488$ & $<0.05$ \\
Collagen accumulation & $2.43 \pm 0.535$ & $2.86 \pm 0.378$ & $2.29 \pm 0.488$ & $2.57 \pm 0.535$ & 0.523 \\
\hline
\end{tabular}

TNF- $\alpha(\mathrm{pg} / \mathrm{mL})$, tumor necrosis factor alpha; TGF- $\beta(\mathrm{ng} / \mathrm{mL})$, transforming growth factor beta; Hydroxyproline ( $\mu \mathrm{g} / \mathrm{g})$.

Histopathological evaluation revealed that inflammatory cell infiltration was high in Group 3 compared to the other groups. Although, PRP decreased the inflammatory cell infiltration in Group 2 compared to Group 1, and in Group 4 compared to Group 3 , the difference was not statistically significant. Similarly, PRP increased the neovascularization, fibroblast activation and collagen deposition, but the difference was not significant statistically for collagen.

\section{Discussion}

PRP was used for the first time in 1987 by Ferrari et $a l .{ }^{11}$ with the purpose of reducing the transfusion of homologous blood products following open heart surgeries. Today, in the field of general surgery, its benefits have been shown in pathologies such as perianal fistulas, hidradenitissuppurativa, liver injury, anastomotic leak and acute abdomen ${ }^{7,12}$. The conviction in literature with respect to PRP, in general, is of the same leaning. The reason for the small number of negative outcomes may be the equipment used, the protocol used to activate the platelet gel, specific characteristics of the patient and the lesion, the platelet concentration used, the way of applying-obtaining it and different storage times ${ }^{13}$.

There are a small number of PRP extraction and collection systems that are approved by the World Health Organization (WHO). Smart Pre P (Harvest Technologies Corp., Norwell, MA) and Platelet Concentrating Collection Systems (3 /Implant Innovations, Palm Beach Gardens, FL.), Sorin Angel, Arteriocyte Magellan (Medtronic, Minneapolis, MN), Biomet GPSII, Depuy Symphony. These systems work to achieve between 2-8 fold increased concentration of platelets ${ }^{14,15}$. PRP may also be obtained using a standard laboratory centrifuge device. But two spins and 
more than one transfer process are needed in this procedure and in the end it might be difficult to preserve the sterility. Additionally, it might pose a problem in terms of the platelets it contains and the key protein amounts contained within them ${ }^{16}$. We were led to obtain PRP using the laboratory centrifuge technique in our study both in terms of cost and also against the possibility of not being able to draw adequate amounts of blood due to the fact that it is a laboratory animal study. PRP obtained in this way is of more limited effectiveness compared to that obtained with special devices by drawing about 50-60 cc of blood. A consensus was reached that the platelet concentration required in order for PRP to achieve tissue healing should be $1,000,000 / \mathrm{Ml}^{17}$. In the analysis conducted in our study, the average platelet concentration was measured as $1,000,000 / \mathrm{mL}$. There are authors who claim that higher concentrations adversely affect wound healing ${ }^{18}$.

Despite medical advances today, in cases with peritonitis - particularly fecal peritonitis- the risk of infections that might develop after closing up the abdomen and subsequent increased incisional hernia is still a major cause of morbidity, especially in emergency surgical procedures ${ }^{19}$. Incisional hernias lead to significant loss of labor, morbidity and affect the quality of life negatively. The only treatment option is surgery. Fascia healing is based on the same principle as wound healing and is closely related to tissue regeneration ${ }^{20}$. The tissue level of hydroxyproline one of the main ingredients of collagen and a good indicator of wound healing objectively reflects the amount of collagen synthesis in the wound. In our study, it was determined that the hydroxyproline level increased in Group 2 specimens (treated with PRP), demonstrating the positive contribution of PRP to wound healing. Heffner et $a l .{ }^{21}$ went one step further, determining that PRP has a positive contribution to myocyte degeneration, collagen organization and fascia tensile strength when used together with collagen products. PRP is said by some authors to cause cutaneous wounds in particular to heal more quickly due to its positive contributions in the dermal matrix stimulation, revascularization and proliferation phases $^{22,23}$. There are also authors who claim that it contributes to wound healing by increasing direct fibroblast proliferation, leukocyte migration and angiogenesis ${ }^{24}$. Histological findings in this study indicated a useful effect on wound healing of PRP by increasing neovascularization, fibroblast activation and collagen deposition. PRP also increased the level of hydroxyproline, which is a positive value for wound healing. From this, we can infer that PRP shows its effect with a complex mechanism, especially in cutaneous wound healing.

In the study conducted by Van Eps et $a l .{ }^{6}$, based on the Modified Hopkins Adhesion Score, a significantly higher adhesion score was obtained after six months in the group which received facial repair with PRP compared to the group which did not (1.63 \pm 0.92 vs. $2.75 \pm 0.70$ ). Also, in this study, it was determined that more recurrence developed after 6 months in the group that was not treated with PRP. In terms of incisional hernia recurrence rates in experimental work, since it has not been recommended much due to working disadvantages (the disproportion of the incision length to the size of the rat, difficult surgical technique), there are very few publications on this subject and these studies are found more among human studies ${ }^{25,26}$.

When, by measuring TNF- $\alpha$ and TGF- $\beta$, we looked at in what way PRP affects wound healing with this mechanism of action, TNF- $\alpha$ levels were found to be significantly higher in all groups compared to the control group $(\mathrm{p}<0.001)$. It was found to be highest in the group wherein fecal peritonitis was created and PRP applied. TGF- $\beta$ levels were detected higher in the PRP treated groups than the control group. These findings in consistence with literature that PRP increases growth factors and through this mechanism speeds up wound healing ${ }^{27,28}$. In many studies that have been carried out, concentrated growth factors have been found to speed up wound healing at a rate of $30-40 \% 0^{29,30}$.

As a result, it might be said that the absence of harmful side effects, the fact that it doesn't shape a widespread scar tissue, doesn't cause malignant transformations, is easily available and can be obtained in a less costly way makes it an alternative - supportive treatment. Several studies in the literature are unanimous with respect to our study. However, further studies are needed to show the protective role of PRP in patients who carry risk factors for incisional hernia (such as obesity, immunosuppressive therapy, diabetes) is investigated.

\section{Conclusion}

When platelet rich plasma was given histologically and biochemicaly as wound healing parameters cellular infiltration, collagen accumulation, and tissue hydroxyiproline levels were not increased but neovascularization, fibroblast activation and TNF Alfa levels were increased and PRP accelerated wound healing.

\section{References}

1 Hall MJ, DeFrances CJ, Williams SN, Golosinskiy A, Schwartzman A. National hospital discharge survey: 2007 summary. Natl Health Stat Rep. 2010;24:1-20 PMID: 21086860.

2 Burger JW, Luijendijk RW, Hop WC, Halm JA, Verdaasdonk EG, Jeekel J. Long-term follow-up of a randomized controlled trial of suture versus mesh repair of incisional hernia. Ann Surg. 2004;240:578-85. doi: 10.1016/j.avsg.2014.10.023.

3 Franz MG, Steed DL, Robson MC. Optimizing healing of the acute wound by minimizing complications. Curr Probl Surg. 2007;44:691763. PMID: 18036992. 
4 Poulose BK, Shelton J, Phillips S, Moore D, Nealon W, Penson D, Beck W, Holzman MD.Epidemiology and cost of ventral hernia repair: making the case for hernia research. Hernia. 2012;16:17983. doi: 10.1007/s10029-011-0879-9.

5 Hodgson NC, Malthaner RA, Ostbye T. The search for an ideal method of abdominal facial closure: a meta-analysis. Ann Surg. 2000;231:436-42. doi: 10.1016/j.jhsa.2013.11.015.

6 Van Eps J, Fernandez-Moure J, Cabrera F, Wang X, Karim A, Corradetti B, Chan P, Dunkin B, Tasciotti E, Weiner B, Ellsworth W. Decreased hernia recurrence using autologous platelet-rich plasma (PRP) with StratticeTM mesh in a rodent ventral hernia model. Surg Endosc. 2015 Nov 17. [Epub ahead of print]. PMID: 26578432.

7 Foster TE, Puskas BL, Mandelbaum BR, Gerhardt MB, Rodeo SA. Platelet-rich plasma: from basic science to clinical applications. Am J Sports Med. 2009;37:2259-72. doi: 10.1177/0363546509349921.

8 Bir SC, Esaki J, Marui A, Yamahara K, Tsubota H, Ikeda T, Sakata R. Angiogenic properties of sustained release platelet-rich plasma: characterization in-vitro and in the ischemic hind limb of the mouse. J Vasc Surg. 2009;50(4):870-9.e2 doi: 10.1016/j.jvs.2009.06.016

9 Anitua E, Muruzabal F, Alcalde I, Merayo-Lloves J, Orive G. Plasma rich in growth factors (PRGF-Endoret) stimulates corneal wound healing and reduces haze formation after PRK surgery. Exp Eye Res. 2013;115:153-61. doi: 10.1016/j.exer.2013.07.007.

10 Lederle W, Stark HJ, Skobe M, Fusenig NE, Mueller MM. Plateletderived growth factor-BB controls epithelial tumor phenotype by differential growth factor regulation in stromal cells. Am J Pathol. 2006 Nov; 169(5):1767-83. PMID: 17071599.

11 Ferrari M, Zia S, Valbonesi M, Henriquet F, Venere G, Spagnolo S, Grasso MA, Panzani I. A new technique for hemodilution, preparation of autologous platelet-rich plasma and intraoperative blood salvage in cardiac surgery. Int J Artif Organs. 1987;10:47-50. PMID: 3570542.

12 Spyridakis M1, Christodoulidis G, Chatzitheofilou C, Symeonidis $\mathrm{D}$, Tepetes $\mathrm{K}$. The role of the platelet-rich plasma in accelerating the wound-healing process and recovery in patients being operated for pilonidal sinus disease: preliminary results. World J Surg. 2009 Aug;33(8):1764-9. doi: 10.1007/s00268-009-0046-y.

13 Eppley BL, Pietrzak WS, Blanton M. Platelet-rich plasma: a review of biology and applications in plastic surgery. Plast Reconstr Surg. 2006;118(6):147-59. PMID: 17051095.

14 Eppley BL, Woodell JE, Higgins J. Platelet quantification and growth factor analysis from platelet-rich plasma: implications for wound healing. Plast Reconstr Surg 2004;114:1502-8. PMID: 15509939.

15 Kevy SV, Jacobson MS. Comparison of methods for point of care preparation of autologous platelet gel. J Extra Corpor Technol. 2004;36:28-35. PMID: 15095838.

16 Martínez-Zapata MJ, Martí-Carvajal A, Solà I, Bolibar I, Angel Expósito J, Rodriguez L, García J. Efficacy and safety of the use of autologous plasma rich in platelets for tissue regeneration: a systematic review. Transfusion. 2009;49:44-56. doi: 10.1111/j.15372995.2008.01945.x

17 Tischler M. Platelet rich plasma. The use of autologous growth factors to enhance bone and soft tissue grafts. NY State Dent J. 2002;68(3):22-4. PMID: 11989332.

18 Marx RE. Platelet-rich plasma (PRP): what is PRP and what is not PRP. Implant Dent. 2001;10(4):225-8. PMID: 11813662.

19 Albertsmeier M, Seiler CM, Fischer L, Baumann P, Hüsing J, Seidlmayer C, Franck A, Jauch KW, Knaebel HP, Büchler MW. Evaluation of the safety and efficacy of MonoMax ${ }^{\circledR}$ suture material for abdominal wall closure after primary midline laparotomy-a controlled prospective multicentre trial: ISSAAC [NCT005725079]. Langenbecks Arch Surg. 2012 Mar;397(3):363-71. doi: 10.1007/ s00423-011-0884-6.
20 van 't Riet M1, de Vos van Steenwijk PJ, Bonthuis F, Marquet RL, Steyerberg EW, Jeekel J, Bonjer HJ. Prevention of adhesion to prostetic mesh: comparison of different barriers using an incisional hernia model. Ann Surg. 2003;237(1):123-8. PMID: 12496539.

21 Heffner JJ, Holmes JW, Ferrari JP, Krontiris-Litowitz J, Marie H, Fagan DL, Perko JC, Dorion HA.Bone marrow-derived mesenchymal stromal cells and platelet-rich plasma on a collagen matrix to improve fascial healing. Hernia. 2012 Dec;16(6):677-87. doi: 10.1007/s10029-012-0941-2.

22 Kimura A, Ogata H, Yazawa M, Watanabe N, Mori T, Nakajima T. The effects of platelet-rich plasma on cutaneous incisional wound healing in rats. J Dermatol Sci. 2005;40:205-8. PMID: 16321720.

23 De Leon J, Driver V, Fylling C. The clinical relevance of treating chronic wounds with an enhanced near-physiologic concentration of platelet-rich plasma gel. Adv Skin Wound Care. 2011;8:357-68. doi: 10.1097/01.ASW.0000403249.85131.6f.

24 Smith SE, Roukis TS. Bone and wound healing augmentation with platelet-rich plasma. Clin Pediatric Med Surg. 2009;26:559-88. doi: 10.1016/j.cpm.2009.07.002.

25 Jin J1, Rosen MJ, Blatnik J, McGee MF, Williams CP, Marks J, Ponsky J. Use of acellular dermal matrix for complicated ventral hernia repair: does technique affect outcomes? J Am Coll Surg. 2007;205:654-60. PMID: 17964441.

26 Breuing K, Butler CE, Ferzoco S, Franz M, Hultman CS, Kilbridge JF, Rosen M, Silverman RP, Vargo D.Incisional ventral hernias: review of the literatüre and recommendations regarding the grading and technique of repair. Surgery. 2010;148(3):544-58. doi: 10.1016/j.surg.2010.01.008.

27 van den Dolder J, Mooren R, Vloon AP, Stoelinga PJ, Jansen JA. Platelet-rich plasma: quantification of growth factor levels and the effect on growth and differentiation of rat bone marrow cells. Tissue Eng. 2006;12(11):3067-73. PMID: 17518622.

28 Nurden AT1, Nurden P, Sanchez M, Andia I, Anitua E. Platelets and wound healing. Front Biosci. 2008;13:3532-48. PMID: 18508453.

29 Man D, Plosker H, Winland-Brown JE. The use of autologous platelet rich plasma (platelet gel) and autologous platelet-poor plasma (fibrin glue) in cosmetic surgery. Plast Reconstr Surg. 2001;107(1):229-37. PMID: 11176628.

30 Everts PA1, Overdevest EP, Jakimowicz JJ, Oosterbos CJ, Schönberger JP, Knape JT, van Zundert A. The use of autologous platelet-leukocyte gels to enhance the healing process in surgery, a review. Surg Endosc. 2007;21(11):2063-8. PMID: 17436045.

\section{Correspondence:}

\section{Kazim Duman}

Elazig Military Hospital, Department of General Surgery

Elazig, Turkey

Phone: +90538-385-9511

drkduman@gmail.com

Received: Jan 14, 2016

Review: Mar 10, 2016

Accepted: Apr 17, 2016

Conflict of interest: none

Financial source: none

${ }^{1}$ Research performed at Laboratory Animal Breeding and Experimental Research Center, Faculty of Medicine, Frrat University, Elazig, Turkey. 